Diánoia, vol. 8, no. 8, 1962

\title{
CRISIS DE LOS FUNDAMENTOS DE LA ETTICA
}

\section{(Hacia una revolución copernicana en la filosofía moral)}

Desde hace más de dos mil años ha llegado a ser un lugar común, en la ética judeo-cristiana y también en la ética profana de Occidente, que el motivo de una acción es el elemento decisivo para la filosofía moral y la pedagogía. Esto significa que se trata, ante todo, de la "intención" de la acción (Gesin. nung, como dice un equívoco término alemán, que induce fácilmente a error), del impulso motivador. Dentro de todo trabajo formativo se justifica, sin duda, esta posición filosófica. Donde no existe buena intención, ni voluntad para acciones éticas valiosas, llegan a carecer también de valor las más profundas teorías acerca de la esencia de lo moral para las formas prácticas de vida.

La significación profunda que han ganado para la historia entera de Occidente la profecía judaica -ocho siglos antes de Cristo- y el fundador del cristianismo, se basa, ante todo, en su llamado a la intención, a los motivos que impulsan toda acción humana. Frente a la obediencia ciega a principios externos ya establecidos, o al temor supersticioso frente a tabúes en los pueblos primitivos, se recurre aquí a un Dios que examina detenidamente, en primer lugar, al que actúa y no el simple y externo cumplimiento correcto de órdenes dictadas desde fuera, de una acción ritual o de cualquier otro mandamiento dentro de las costumbres ya determinadas de un pueblo.

No los sacrificios animales o humanos, ni el cumplimiento de otros usos religiosos y sociales, sino el sentimiento interno de solidaridad con los demás, la disposición a la ayuda social y el amor a lo divino "con toda la fuerza y toda el alma", son aquí verdaderos criterios de lo moral. No la simple realización de ciertas acciones prescritas sino la pureza de los motivos de los que resultan los actos, son ahora lo decisivo.

La pasión dirigida a esta pureza interna de la intención en los discursos proféticos de Amós, Isaias, Jeremías y Jesús de Nazareth, significa una grandiosa negación ética de las concepciones morales corrientes del Antiguo Oriente y del mundo de los pueblos primitivos, hasta la época moderna. Es cierto que el Nuevo Testamento habla ocasionalmente de que "por sus frutos los conoceréis". Pero no puede haber la menor duda de que el Nuevo Testamento, más aún que ciertas tendencias del judaísmo talmúdico, sostiene frente a esta ética del resultado una decidida ética de la intención. En la Edad Media esta tendencia moral cristiana es representada, con particular 
eficacia, por espíritus como Pedro Abelardo ${ }^{1}$ y Hugo de San Víctor. ${ }^{2}$ Incluso la extraordinaria fuerza del influjo que surge de la ética kantiana, descansa esencialmente en su llamado a la conciencia, a la "buena voluntad", a las solas intenciones, en oposición a la consideración del éxito, del logro de la felicidad por medio de una acción. ${ }^{3}$ Entre los innumerables pensadores del siglo XIx, que de ninguna manera se hallan bajo la influencia del "cumplimiento del deber por el deber" de Kant y de su ética de la intención pura, podría citarse, en cierto modo, a John Ruskin ${ }^{4}$ quien rechaza igualmente la ética del éxito; y aún ahora asistimos al despertar de la intención interior pura del hombre en la pedagogía teórica y práctica, lo que ha permanecido, con derecho, con un valor decisivo.

¿Pero puede valer lo mismo también para la fundamentación de la ética? Yo creo que, contra semejante traslado de una tesis de la pedagogía a la filosofía moral, pueden elevarse las más graves objeciones, aun cuando a menudo se identifica la ética con la doctrina de la educación o con la edificación moral; y las objeciones contra la ética de la intención pura - de las cuales quisiera destacar sólo tres- son, me parece, de significación cardinal para la neo-fundamentación de una filosofía moral que pueda mantenerse seriamente ante las perturbaciones peligrosas de la crisis actual de nuestro pensamiento ético.

\section{Las intenciones y su valor no son dados en la evidencia}

Primero - y ésta es la más obvia, comprensiva, pero de ninguna manera la más profunda de las dificultades que surgen aquí ante nosotros- los

1 Petrus Abaelardus, Ethica seu scito te ipsum II in Patrologiae cursus completus ed. P. Migne, Series II, Ecclesia latina, Paris, 1844, tomus 178, por ejemplo, pág. $65_{2}$ C: "Bonam quippe intentionem... rectam in se dicimus; operationem vero, non quod boni aliquid in se suscipiat, sed quod ex bona intentione procedat. Cf. ibid., p. 65o B: "Opera... omnia in se indifferentia nec nisi pro intentione agentis bona vel mala dicenda sunt"; y véase pág. $650 \mathrm{c}$.

2 Hugo de San Victor explica, ciertamente, en De sacramentis christianae fidei, Patrologia, Series latina, ed. Migne, tom. 176, pág. 561 B: "Non est voluntas si non operatur quod potest"; pero esto consiste en que "totum ergo meritum in voluntate est. Quantum vis, tantum mereris". Cf. De fructibus carnis et spiritus, ibid., pág. 997 sigs. de los Análisis de múltiples virtudes, esto es, de motivos como portadores esenciales del valor ético, y los desarrollos del Arbor virtutum, árbol de la virtud, cuya raíz es la humilitas, la humildad, y sus frutos son las cuatro virtudes platónicas y las tres virtudes cardinales cristianas, junto a muchas otras; mientras que la raíz del Arbor vitiorum, árbol del vicio, constituye la superbia, la soberbia, con muchos vicios como frutos.

3 Ver Kant, Fundamentación de la metafisica de las costumbres, en la primera sección (Grundlegung zur Metaphysik der Sitten, ed. Th. Fritzsch [Reclam], 1. Abschnitt, S. 22), por ejemplo, incluso si "nada de ella (la buena voluntad) se cumpliera... sería, sin embargo, como una joya brillante por sí misma, como algo que tiene su pleno valor en sí mismo".

4 John Ruskin, Unto this Last, 1862, por ejemplo, pág. 21: "Nadie conoce, o puede 
motivos de la acción humana, esto es, aquellos impulsos del sentimiento y representaciones intelectuales que los acompañan, que impelen nuestra acción (independientemente de la consideración de la acción misma), nuestros motivos e intenciones permanecen para siempre profundamente ocultos dentro del corazón del que actúa.

Puede ser que en muchos casos corrientes logremos captar, con aproximación, los motivos morales de nuestros semejantes. Sin embargo -y mucho más en los innumerables e importantes casos de decisiones en conflictos morales- no se nos da nunca con evidencia el verdadero carácter de los motivos del otro. Debemos concluirlo de su comportamiento visible. No sólo los detectives ni los maledicentes innatos de ambos sexos tienen un talento especial para interpretar los motivos de sus semejantes por el lado malo; y, viceversa, no sólo los enamorados y los historiadores nacionalistas acostumbran explicar a sus héroes y heroínas por el lado bueno; todas las conclusiones acerca de los motivos de los otros deben, según su naturaleza, permanecer como suposiciones de $X$ y no se puede, de ninguna manera, aceptar una garantía de su adecuación.

Pero lo que dificulta considerablemente lo anterior es que también nuestro juicio acerca de nuestros propios motivos está expuesto, incluso en la autocrítica bien dirigida, a graves posibilidades de error. Verosímilmente la mayoría de nosotros tiene, sin exceptuar a muchos de los peores criminales políticos, un talento envidiable para encontrar todos sus motivos honrosos o incluso excelentes. Pero también aquí se dan, de manera opuesta, naturalezas bastante sensibles e hipersensibles que se inclinan a sospechar injustamente de sus propios motivos, que - por sentimientos de culpa sin base y autoacusaciones- sufren y aun se derrumban. Psicólogos de siglos pasados y de nuestro propio tiempo han reafirmado semejantes observaciones acerca de la valoración de la intención humana, con tal cantidad de ilustraciones, que toda insistencia en el tema sólo podría sacar a luz completas trivialidades.

Pero si se pregunta: caun si se nos concediera voluntariamente que, ni en el buen ni en el mal carácter de nuestros motivos se da en la evidencia -contra todas las afirmaciones de predicadores y teóricos de la moral pura a priori- no ocurriría algo mucho peor con los resultados de nuestros actos? Las dificultades que se presentan por el lado de la "ética de los resultados" no pueden menospreciarse de ninguna manera.

Indudablemente las predicciones de las consecuencias de nuestras acciones en general son mucho más inexactas que las predicciones en la física o incluso en la medicina. Nuestros psicólogos y nuestros sociólogos no trabajan, ciertamente, con aproximaciones de tanta precisión como los físicos, de conducta. Pero todo el mundo puede conocer... qué es un acto justo o injusto." 
precisión que, empero, no es absoluta sino en casos especiales, y que, cuando más, se considera desarrollable en un sentido preciso. Probablemente la aproximación a precisión semejante sea difícilmente alcanzable en las ciencias sociales y en la psicología, a causa de la complejidad del objeto de investigación.

Pero, y ésta es mi opinión acerca del punto central de esta cuestión, en la física como en los resultados de nuestras acciones, hay en juego un factor decisivo que, en oposición a todos los factores del análisis de las puras intenciones éticas, tiene auténtico carácter de evidencia. Si en la física son los datos sensibles, en las consecuencias de nuestros actos en la ética son los sentimientos de placer y dolor.

A través de los siglos se ha rebajado el valor del conocimiento sensible para nuestra captación de la verdadera realidad objetiva del mundo exterior. Desde que Parménides intentó construir una imagen del verdadero Ser, una auténtica ontología eliminando las "falsas apariencias" de las sensaciones humanas, se han menospreciado cada vez más, por la metafísica, las percepciones sensibles como inadecuadas para la captación de la realidad objetiva. Tuvo, ante todo, que realizarse una revolución copernicana, con la fundamentación de la moderna ciencia de la naturaleza, y filosóficamente desde que Kant abrió el camino a la idea de que los sentidos deben ser exonerados de la acusación de "engañosos", de que deben ser liberados de la "mala fama" en la que los tenía el entendimiento. 5

En la ética, sin embargo, dominan hasta ahora en todas partes concepciones fundamentales "pre-copernicanas"; la creencia en principios absolutamente válidos, objetivos, captables inmediatamente, en los cuales puede aprehenderse la esencia interna de lo moral, independientemente de toda relación con las percepciones sensibles o los sentimientos vividos empíricamente. O la creencia en "intrinsic values", que no se presentan en forma "naturalista" ni como percepciones ni como sentimientos; o la creencia en valores esenciales objetivos, respetables como universalmente válidos, esencias en el sentido de la significación metafísica de las ideas platónicas, que la explicación moderna de la naturaleza ha dejado a un lado cada vez más. Todas estas teorías, empero, el "neo-deontologismo" inglés, las teorías de los valores americanas, francesas y alemanas, tienen en común el utilizar esencialmente sólo elementos de la intención para la fundamentación de la ética. Pues los valores son, en gran medida, sólo motivos de acciones hipostasiados en esencias objetivas, como los valores del amor, del honor, del sentimiento de la justicia, etc. En oposición a la investigación moderna de la naturaleza se rechaza en las teorias éticas dominantes hoy en día, toda fundamenta-

5 Kant, Anthropologie in pragmatischer Hinsicht, Werke, ed. Ernst Cassirer, 1912, Bd. VIII, pág. 28 sigs.: "Apología de la sensibilidad", contra la "mala fama" en la que la tenía el entendimiento. 
ción definitiva del valor real y pleno en vivencias sensibles y concretas. Como una diferencia radical frente a todas las interpretaciones de la naturaleza, se rechaza en la filosofía moral el principio de la verificación necesaria de las leyes universales por medio de los datos empíricos de los sentidos. Semejante verificación se muestra, incluso, como "sin objeto" o "absurda".

Como antes los metafísicos se opusieron a explicar la esencia "objetiva" del Ser, en último término, por el recurso a las más "subjetivas", humanas, demasiado humanas, constantemente variables, captaciones sensibles; con preocupación mucho más comprensible, se niega el teórico de la ética hasta nuestros días a abandonar la fundamentación de la moral objetiva, los fundamentos de toda moral obligatoria universal, en última instancia, al dominio de un supuestamente "subjetivo puro", "imprevisible y oscilante" sentimiento de humano placer y displacer. Es fácilmente comprensible que después de que se nos ha quitado, cada vez más, la creencia en un ser en sí, invariable, en la metafísica; después de que la investigación de la naturaleza, a pesar del uso de hipótesis abstractas y conclusiones deductivas, se ha entregado finalmente a la verificación, por medio de las cambiantes percepciones sensibles, se hizo entonces más preciso, apoyarse, al menos en la moral, en principios objetivos puros, totalmente separados del supuesto influjo de vivencias empiricas subjetivas.

Como los niños tratan de calmar su miedo en la noche por medio de canciones infantiles, así los grandes moralistas hablan con mayor fuerza y excitación de valores y leyes morales simples y elementales y de evidencia absoluta, mientras más angustiosa es la oscuridad de las relaciones de valores - para todos nosotros_ que todo juicio ético objetivo e incorruptible tiene que superar. Un gran número de repetidores filosóficos no han visto, o no han querido ver, sin embargo, por estrechez o ceguera, la oscuridad que hay que penetrar, y por ello anuncian victoriosamente que por la revelación y la razón está grabado, en todo corazón humano, con letras claras y luminosas, lo que significa el bien y el mal.

Así como antes en el desarrollo de la metafísica, así también en la ética de la eliminación de la vivencia empírica, no se ha podido salvar, de ninguna manera, de la "skepsis" a nuestra creencia en supuestos principios verdaderos, invariables, y en valores esenciales a priori. El positivismo lógico, que de Viena se extendió a Inglaterra y América, ha rechazado, no sin razón, como proposiciones propiamente sin sentido, a todas las teorias morales que pretenden apartarse de la verificabilidad de sus afirmaciones por medio de datos empíricos.

Si se convierte a la sensibilidad, a la vivencia empírica concreta en el fundamento legítimo de todo conocer y comprender en la ética, dándole su plena justificación, entonces se puede —-sobre una base semejante-, me parece, construir con mayor confianza una teoría que pueda tomarse, en cierta 
manera; como no menos sutil que las teorias de la ciencia natural. Pues nuestras vivencias de dolor y placer son, en verdad, de acuerdo con su esencia, con su realidad más íntima, todo lo contrario a algo engañoso y meramente subjetivo. Nuestras alegrías, satisfacciones, sufrimientos y depresiones son datos objetivos, realidades "férreas", tanto como nuestras sensaciones. Al manifestarse en las consecuencias de nuestras acciones, no pueden dejar de ser consideradas a causa de nuestros caprichos y arbitrariedades.

Lo que yo o algún otro experimentamos como placer, es y sigue siéndo pla. cer, delimítese como se quiera este sentimiento; y sigue siendo placer ya se trate de que lo viva Nerón o Francisco de Asís. Como placer, sin embargo, es - aun cuando siempre limitado- un valor y no puede ser convertido en un no valor. Inclusive el placer en là alegría del mal, en la medida en que se considera únicamente el elemento placer, es un valor. Sólo puede convertirse en un no-valor en la medida en que el placer por el mal se adquiere definitivamente a costa de un gran sufrimiento de otro, por lo tanto cuando en conjunto condiciona mayor dolor que placer, y en la medida en que es el signo de que el hombre que experimenta este placer por el mal lo experimenta siempre (no una vez accidentalmente) con base en semejante gran sufrimiento. Incluso el placer que experimenta el más bajo criminal, es qua placer un valor, un positivum.

Algunos moralistas ingleses han hecho el intento en los últimos años de sostener con grandes esfuerzos la tesis supra-puritana de que un mundo en el cual el criminal no experimente ningún placer con el ejercicio de su maldad, sería mucho más perfecto que aquel en el que experimentara este placer en las mismas circunstancias. ${ }^{6}$ ¿Pero por qué tiene que ser el moralista siempre mucho menos generoso que la naturaleza, que otorga y distribuye, voluntariamente, al cruel malhechor al realizar sus crímenes, una alegría - aunque casi nunca pura-, ya que él no es seguramente envidiable por su constitución casi siempre patológica? ¿Cuando la espantosa desgracia que aquí es causada no puede ser disminuida, qué pasa entonces con el descrédito del sentimiento de placer que la acompaña?

No, no son los sentidos mismos ni los sentimientos humanos los que engañan. No es el placer en la alegría del mal ni el placer del criminal lo que representa aquí lo negativo, un no-valor, y lo que entregaría nuestra vida sentimental a la mentira, cuando normalmente consideramos a todo placer como un valor. Es el tácito juicio erróneo el que acompaña aquí fácilmente a una verdadera vivencia. Es un juicio erróneo el que el placer en el goce del mal y el placer en el crimen, ambos acompañados necesariamente con mayor sufrimiento de otros, pueden otorgar, sin embargo, al fenómeno total antedicho un valor total positivo. Si nos resignáramos a considerar

6. Ver, por ejemplo, Sir W. D. Ross, The Right and the Good, 1930, pág. 151 y H. W. B. Joseph, Some Problems.in Ethics, 1931; págs. 9o sigs. 
el placer qua placer como valor resultaria imposible toda orientación consecuente tanto en la vida del sentimiento como en la conducta ética del hombre.

De acuerdo con mi opinión, no es en los aparentemente definitivos y objetivos valores esenciales ni en los supuestamente objetivos, puros e intocables principios morales, sino -como en la imagen copernicana del mundo a pesar de la apariencia - en las al parecer plenamente subjetivas y fluctuantes vivencias de los sentimientos del hombre, en donde puede construirse una teoría consecuente de la interpretación y valoración de los fenómenos mencionados. Pero acepto voluntariamente, que en el sentido de la construcción de una "ética del resultado" hay que superar aún cientos de posibles equívocos que se hallan en esta dirección, antes de que Ias concepciones fundamentales defendidas hasta aquí puedan aparecer como aceptables.

\section{Prejuicios en la designación de las intenciones}

Una larga serie de objeciones contra la ética pura de las intenciones ha sido expuesta ya, desde hace mucho tiempo, por un gran moralista bastante menospreciado. Jeremías Bentham, jurista inglés del siglo xIx, el iniciador y más profundo teórico del hedonismo moderno, publicó en el año de 1817 un folleto de pocas páginas, que incluso en la literatura acerca de Bentham ha permanecido poco atendido: "A Table of the Springs of Action". Bentham desarrolla aquí con mayor intensidad que en su conocida obra fundamental de 1789 , el mismo asunto, aun cuando con diferentes palabras y ejemplos: en ninguno de los lenguajes conocidos por nosotros -escribe - se da una nomenclatura realmente imparcial para una caracterización moral sin supuestos de los motivos humanos, la mayoría dominante de todos nuestros términos para la designación de los impulsos (motivos) humanos contiene ya una valoración positiva o negativa.

Si de acuerdo con ello consideramos una acción como moral y como fundamento señalamos únicamente el que está justificada éticamente de antemano la moralidad de su motivo, incurrimos en un círculo vicioso. En realidad no hemos fundamentado de ninguna manera el valor moral de la acción. Hemos supuesto ya, de antemano, la moralidad de ese acto sin ninguna justificación. Si hubiéramos tomado la acción como inmoral, no hubiéramos aplicado el predicado elogioso para la caracterización de su motivo, sino uno de los muchos términos a nuestra disposición para condenar sẹmejante motivo.

En todas las argumentaciones semejantes damos la impresión de demostrar algo sin hacerlo. Suponemos lo que hay que probar como ya probado en la medida en que al fundamento de la prueba (al motivo) prestamos de antemano - a nuestro gusto - un nombre que contiene ya en este puro nom- 
bre el resultado de la prueba (el contenido moral del acto total) independientemente de nuestra prueba.

Esto significa que si, por ejemplo, declaro ético un acto porque su motivo fue el patriotismo, con ello todavia no he establecido justificación alguna de su moralidad. Sólo he confirmado una valoración positiva del acto por el hecho de que escogí un predicado de aprobación moral para designar su motivo. Si hubiera querido juzgar verdaderamente sin prejuicio, debería haberme preguntado primero si el móvil, el impulso humano del cual provino este acto ¿merece realmente el término elogioso "patriotismo" o más bien el término denigrante "chauvinismo"?

La mera consideración y análisis del motivo - por cuidadosos que seanno pueden proporcionarme el más mínimo fundamento objetivo para su valoración moral. El mismo motivo del mismo acto puede ser considerado como amor auténtico, abnegación desinteresada, o - en burdo contrastecomo esclavitud, servilismo y amor ciego. La misma intención en la misma conducta humana, puede juzgarse éticamente en forma por completo distinta, o como avaricia o como virtud del ahorro. La incompatibilidad de los sistemas morales completamente enemigos que se enfrentan, de la cual es testigo la historia universal y de nuevo y en particular nuestro tiempo, se manifiesta precisamente en que uno y el mismo acto, con uno y el mismo motivo, puede ser —dogmáticamente y sin consideración alguna de las consecuencias- alabado como resultante de la más ejemplar grandeza de intenciones, y simultáneamente vituperado como manifestación de la más miserable y baja moralidad.

La misma intención, combatida por la moralidad judeo-cristiano-budista como crueldad absurda y bestial, significa para la moral de los amos, el maquiavelismo, e incluso par la moral pública común - tanto de pueblos antiguos como modernos- una manifestación de fuerza viril sin sentimentalismo. El amor a la paz y el alto espíritu de reconciliación elevados allá a ideales, se consideran aquí condescendencia deshonrosa y débil.

El cambio radical de la moralidad integral de la antigüedad greco-romana a la del cristianismo, se lleva al cabo de modo característico en que, por

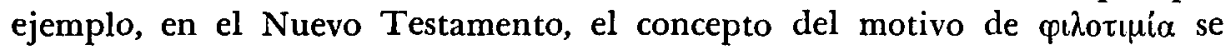
considera todavía en el sentido elogioso de la Antigüedad, pero en la exi-

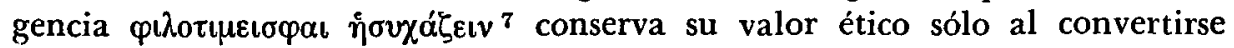
paradójicamente en lo contrario. La pidotuía, o sentido del honor, sólo se alaba aún, en cuanto significa, en verdad, la renuncia a todo pundonor y en cuanto se convierte en silencio, en humildad pura; mientras que el antiguo sentido del honor se rechaza como vanidoso afán de reputación mundana.

Bentham, basándose en consideraciones semejantes, ha establecido una

7 San Pablo, Primera Epistola a los Tesalonicenses IV, go sigs. 
tabla, una lista, de motivos de las acciones humanas en la que se separan rigurosamente los distintos términos de elogio para los correspondientes motivos, de los términos reprobatorios y de los términos neutrales. ${ }^{8}$ Llegó al resultado, poco sorprendente, de que en general el idioma cuenta con muchos más términos para lo negativo y lo que provoca la falta de estimación, que para lo positivo y afirmativo. Como se ha observado ya con frecuencia, el vocabulario de Dante es mucho más rico en su representación del infierno que en la del paraíso. ${ }^{2}$ El vocabulario de los idiomas es paupérrimo en materia de términos estrictamente neutrales, carentes de prejuicios e imparciales, para la caracterización de los motivos.

Es por eso por lo que Bentham hace la curiosa proposición de que, para un análisis rigurosamente imparcial de los motivos humanos, se admitan, por lo pronto, solamente aquellos términos que no son ni de elogio ni de censura; y como los idiomas no poseen de ninguna manera suficientes palabras de esta índole, propone que sean creados términos nuevos, artificiales y totalmente neutrales, para caracterizar a todos los motivos. En la terminología de Bentham, por lo tanto, no se debe hablar ni de avaricia ni de sentido del ahorro, ni de patriotismo ni de chauvinismo, ni de amor a la paz ideal, ni de condescendencia deshonrosa, sino únicamente de motivos de interés económico, interés en un estado o nación, interés en el arreglo de los conflictos renunciando al uso de la fuerza, etcétera.

Sólo después de haber caracterizado un motivo por medio de un término completamente libre de valoración, se puede proceder a determinar si el acto concreto, inspirado en tal motivo, tiene que ser considerado moral o inmoral. Esta valoración ética, sin embargo, sólo puede hacerse con miras a la magnitud de sufrimientos o placeres que aparecen en las consecuencias de este acto. El motivo del acto, aislado del resultado, no puede en modo alguno emplearse como fundamento para un juicio moral imparcial. Esto significa, en resumen y conclusión, que toda ética que con orgullo se limite a juzgar los motivos de una acción, declarando secundarias las consecuencias de esta acción, sólo puede terminar en una pseudo-fundamentación dogmática de sus juicios de valor, o de otra manera esta ética deberá admitir, de antemano, que es conscientemente parcial y acrítica. Y, en correspondencia, toda ética que se base en valores esenciales (como el amor, él honor, la sabiduría, lo sagrado) o en principios universales de la intención (como el impe-

8 The Works of Jeremy Bentham, 1843, vol. I, pags. 205 sigs., "A Table of the Springs of Action".

9 Ver, por ejemplo, A. Schopenhauer, El mundo como voluntad y representación (Die Welt als Wille und Vorstellung, Buch IV, Sämtliche Werke, ed. Eduard Griesebach, 1905, S. 430): "¿De qué otra parte ha tomado Dante el material para su infierno si no es de nuestro mundo real?... En cambio, cuando llegó a la tarea de mostrar el cielo y sus alegrías, se enfrentó a una dificultad insuperable, porque justamente nuestro mundo no ofrece casi ningún material para algo semejante." 
rativo categórico, la ley de la justicia, etc.), a pesar de reclamar la validez absoluta de sus principios de valor e intención, abrirá en realidad las puertas al relativismo tan pronto como se trate de juzgar comportamientos concretos por medio de la aplicación de tales principios abstractos.

Qué poco consuelo sería, para una ética, si tuviera que admitir que in. cluso la exterminación de muchos compatriotas "antipatrióticos" en campos de concentración, podía ser dictada sinceramente por la "idea del amor" (plena de valor "absoluto" en sí) a ese pueblo, que aun el más sangriento fanatismo religioso representaría un celo por el valor absoluto de lo sagrado, qué poco consuelo si tuviera que decir frente a todo esto que la ética no puede ni necesita preocuparse de esas realizaciones "inadecuadas" de los valores absolutos en la vida real.

Esta manera de mirar con desprecio a la "mera realidad" cree poder tolerar son toda serenidad aun el que los actos más vulgares y abyectos se vanaglorien de su servicio a los más sublimes valores. Sin embargo, de hecho, esta indiferencia en lo que toca a las consecuencias empíricas de los actos humanos, conduce forzosamente al fracaso completo en la ética. Lo que sería admisible para una tipología meramente descriptiva de los valores, una mera caracterización de los valores o leyes éticos, resulta completamente insuficiente para el juicio ético. En ese caso, los valores, imperativos y leyes morales para juzgar el comportamiento humano concreto, siguen siendo conceptos genéricos universales que suponen tácitamente y sin ninguna crítica, la separación de todo lo que puede subsumirse bajo estos conceptos; y de todo lo que debe excluirse por tener carácter de anti-valor. En la ética, sin embargo, es esta separación precisamente lo único decisivo."

3. Dependencia de la valoración de las intenciones éticas de los resultados de los actos inspirados por ellas

Si de acuerdo con lo anterior, la crítica aniquiladora de Bentham relativa a una pura ética de motivos, puede aplicarse también a la ética absolutista de los valores y de los principios abstractos de la intención, ¿podemos concluir entonces que los motivos e intenciones son insignificantes en todos sentidos para juzgar las acciones humanas? ¡De ninguna manera! E1 pedagogo, el predicador y el metafísico de la moral, tienen mil veces razón si se niegan a considerar como punto de partida y núcleo de sus esfuerzos a cualquier otra cosa que los motivos, las intenciones de los hombres, en oposición a las "meras" consecuencias de los actos inspirados por estas intenciones.

¿Qué clase de educador sería aquel que - como el jurista - se limitara voluntariamente a contemplar sólo la corrección, la legalidad, la impertinencia, lo punible en los actos, en vez de atenerse de inmediato a los móviles que inspiran toda acción humana! $\mathrm{Y}$ tanto el metafísico como el estadista 
tienen base suficiente para mantener que todo puede esperarse de hombres de buẹna intención, de una juventud plena de motivos puros. En cambio, donde los motivos de los hombres son débiles o bajos, alli todo está perdido a menos que el educador logre transformar las intenciones.

Sin embargo, aunque todo esto es obvio y fue señalado muchas veces en el curso de los siglos, toda pedagogía tiene que ser precedida objetivamente por una "teoría de la ética" y objetivamente toda metafísica tiene necesariamente como fundamento una teoría del conocimiento. ¡Pobre del educador y del metafísico que trate de negarlo! Nunca darán cuenta, ni a sí mismos ni a otros, de hasta qué punto sus construcciones "ontológicas" son productos de su fantasía, o de hasta qué punto apoyan con nombres pomposos e idealistas los motivos más infames.

Los que "aniquilaron totalmente" la fe y la moralidad, no fueron los críticos "racionalistas" del conocimiento, como Maimónides o Galileo, Kant o Bentham, como en su tiempo lo temieron la ortodoxia y sus asustados pedagogos. Los enemigos verdaderos de las grandes tradiciones religiosas y éticas no son nunca la "skepsis" sincera ni tampoco la desesperada, son, en el pensamiento: la indiferencia y el convencionalismo; en la acción: la indolencia y la rutina; y, crecidas a su sombra, las verdaderas fuerzas satánicas del retroceso al ciego instinto animal, las cuales, desgraciadamente, comparten esta ceguera con algunas formas de creencia tradicional.

Significa, en mi opinión, un menosprecio de las fuerzas internas, propias de lo "religioso-moral", si en su análisis se rechazan de antemano y sin investigación, los métodos de la razón pura, de la ciencia natural "profana". En cuanto esta razón nos hace posible reflexionar éticamente sobre la base firme de la teoría del conocimiento, y obtener visiones nuevas e imparciales dentro de la confusión compleja de la vida ética, por medio -aunque parezca paradójico- de hipótesis, de divisiones y síntesis metódicas, tal crítica del conocimiento, en mi opinión, debe considerarse más bien ayuda que estorbo en la interpretación de los complejos "dados" de la vida moral.

En la vida diaria podemos aceptar las apariencias, dejando salir al sol por el este y ponerse en el oeste. Pero si debemos dar cuenta de los verdaderos movimientos de los astros, el referirnos a la "realidad" evidente de las cosas no nos protegerá de las complicaciones más graves y de lo incomprensible en los cálculos respectivos. Todavía peor será la situación en la ética, si concedemos inocentemente el primer rango indiscutible a las intenciones, si no las separamos "metódicamente" de los entrelazamientos reales con los otros elementos de los actos moralmente relevantes, y si no nos atrevemos a adjudicar a los resultados la importancia primera, en vez de una secundaria. En una ética críticamente fundada, las intenciones no se declaran tampoco irrelevantes, así como en la astronomía de Copérnico no se niega la salida del sol por el este, en tanto que experiencia de los sentidos. 
Sin embargo, y a pesar de las apariencias, tanto en la fundamentación crítica de la filosofía moral como en la astronomía moderna, se reduce un fenómeno central "evidente" a una posición secundaria, y lo evidentemente secundario sube a la posición central.

La tercera objeción contra una ética de puras intenciones consiste en lo siguiente: para el moralista crítico los motivos sólo pueden considerarse morales en cuanto que sean indicios para producir resultados principalmente placenteros, e inmorales solamente en cuanto que indiquen principalmente la provocación de sufrimientos. Lo cual quiere decir que la instancia suprema para juzgar del valor y no-valor éticos, no puede estar, paradójicamente para él, en los motivos, sino exclusivamente en las consecuencias del comportamiento humano. Aun el mártir, si acepta voluntariamente los sufrimientos más penosos, no lo hace ni puede hacerlo por el sufrimiento mismo, sino porque la beatitud que adquiere para si y para el triunfo de su causa por medio del dolor e incluso de su sacrificio, es mayor que toda la alegría que pudiera comprar traicionando su causa o sirviendo a una causa indigna. Empero un sufrimiento escogido voluntariamente, por el sufrimiento mismo, que no proporcione placer elevado alguno, ni para el que sufre ni para otras personas, en el caso de que pudiera encontrarse, sería inmoral o por lo menos sin valor. Se puede dudar fácilmente de la posibilidad de escoger un semejante sufrimiento que no incluyera la más mínima satisfacción, ni siquiera el placer considerable de la desesperación abierta y obstinada en contraste con la contrición pasiva y silenciosamente soportada.

Todos los motivos alabados, como el amor, la bondad, el sentimiento del honor y los demás del mismo género, se pueden considerar predominantemente como morales, únicamente si, por lo general, es mayor la felicidad que el dolor que ocasionan. Sin embargo, es inmoral todo amor materno exagerado que de un hijo hace una persona incapaz para la vida, causándole más sufrimiento que alegría. Además todo sentimiento del honor es inmoral si está dispuesto, por una ofensa al honor, a arruinar al mundo. Aunque sea pleno de gran valor y dignidad moral el proverbio romano fiat justitia, pereat mundus. como correctamente lo consideraron Bentham, Hegel y también Herder, ${ }^{10}$ es más una frase presuntuosa, una cátedra de agradable

$10 \mathrm{~J}$. Bentham, An Introduction to the Principles of Morals and Legislation, chap. II, sect. 11: "Fiat justitia, ruat coelum", es una máxima "tan llena de extravagancias... como de armonia" de lenguaje. O cf. Bentham, The Limits of Jurisprudence Defined, ed. Charles W. Everett, 1945, pág. 284: "Though heaven were wrecked, let Justice be adhered to. Heaven may always be preserved"; Hegel, Grundlinien der Philosophie des Rechts, 1821, Werke, $183_{2}$ ff., vol. vill, 196, 130: "Se puede hablar, en forma sublime, del Deber y del Derecho, y esto nos agranda el corazón; pero el derecho no es la bondad sin el bien, fiat justitia no debe tener como resultado pereat mundus; compárese con argumentos semejantes en Kalligone de Herder (Werke, ed. Suphan, Bd. 22, 1880, S. 276), o en Briefe zur Beförderung der Humanität, 8. Sammlung, $179^{6}$ (Werke ed. Suphan, Bd. 18, S. 86), en la Polémica contra Kant. 
sabiduria, que una verdad ética. Un procedimiento supuestamente justo, que puesto en práctica implique el sufrimiento y la aniquilación de la humanidad, no puede - de ninguna manera - representar un juicio que pretenda ser un juicio humano-moral.

Por el contrario, inclusive el odio contra un malhechor qua malhechor es un motivo moral si libera al mundo del sufrimiento por medio de la enemistad, contra el que lo causa. Además, se puede aceptar que la lucha sin odio contra un criminal es, desde el punto de vista moral, más elevada que una lucha llena de odio, y que el malcriar a un niño por maldad es peor que el malcriarlo por amor materno. Pero aun así, el odio -en el primer caso- es motivo pleno de valor, y el amor -en el segundo caso- un motivo sin valor; aunque el amor, por lo general, tiene que reconocerse como moral y el odio como inmoral, precisamente porque normalmente las mayores alegrias resultan del amor y los mayores sufrimientos surgen del odio.

Seguramente son extraordinariamente grandes las dificultades en la apreciación de mayores o menores felicidades y tristezas y no pueden tratarse en este extenso y complicado campo de cuestiones; sin embargo, estas dificultades no son para el conflicto principal entre la moral brutal de la fuerza y la moral de la consideración humana y la bondad, tan desesperadamente insuperables como la determinación de la moralidad o inmoralidad de los motivos y de las intenciones en sí.

Si con el uso del término "intención" se disimulan más estas dificultades que con el término "motivo de la acción", se debe esencialmente a que con la "intención" se incluye, por lo menos tácitamente, la consideración de las consecuencias normales de las acciones que surgen de motivos determinados. En realidad, naturalmente, la intención y las consecuencias de la acción están estrechamente ligadas en el acto realizado como un todo. Esto, desde luego, no indica que los diversos elementos de la acción no puedan distinguirse metódicamente para hacer posible la apreciación de las diversas contribuciones de los varios elementos para la valoración moral del acto total. Y entonces se muestra, por la teoría del conocimiento que la cualidad del resultado del acto es para la determinación ética de su valor total el momento decisivo.

Hasta qué punto es, y debe ser, éste es el caso, es decir, cuán poco el motivo de la acción puede desempeñar un papel principal en el juicio crítico ético, se ve quizás de la manera más sencilla, por medio de un experimento del pensar y con la ayuda de este experimento se puede resumir al máximo, nuestra tercera objeción contra la ética de la intención pura. Supongamos un orden lógico del mundo, completamente posible, en el cual la bondad y el amor crearan mucho más sufrimiento que alegría. Éste no sería el mundo de Zarathustra, pues en él desempeña un papel muy importante la nobleza y la generosidad del héroe. Sería un mundo tal como el que les hubiera gus- 
tado imaginar a las "bestias rubias" si tales bestias hubieran tenido el tiempo y la habilidad para dedicarse a semejantes consideraciones. Sería un mundo en el que, al contrario del que todos conocemos, la bondad auténtica produciría males, y también incluso la verdadera y poderosa bondad, que no tiene nada que ver con el sentimentalismo ciego y sin fuerza del "todo garantizado" ni del "todo-perdonar". Suponiendo ahora que existiera un tal mundo lógico, completamente sin contradicciones, ¿valdrían aún el amor y la bondad como motivos especificamente morales?

O por el contrario, supongamos un orden del mundo en el que el odio y la crueldad produjeran una felicidad mucho más duradera, intensiva y completa, para la humanidad entera, que la bondad y el amor, ¿podrían figurar aún el odio y la crueldad esencialmente como motivos inmorales? De manera que es evidente que no son las misteriosas y ciegamente aceptadas cualidades del motivo del odio, las que merecen ser calificadas como absolutamente malas en si, y no son las ocultas e incaptables cualidades del motivo del amor las que lo elevan a virtud. Es experiencia básica y elemental, una de las pocas experiencias seguras de nuestra vida, la de que el odio conduce al sufrimiento y el amor a la felicidad. Son estas experiencias - y no incaptables cualidades a priori- las que hacen del predominio del motivo de la bondad, un valor moral y del predominio del odio, un no-valor.

Es decir, que las intenciones sólo pueden recibir su afirmación última de valor por los resultados empíricos de la acción, y no por el contrario las consecuencias de la acción de las intenciones, si es que queremos situarnos en un punto de vista racional, imparcial, sin prejuicios, y más allá de la moral del amo y del esclavo. Únicamente el viejo principio, el menos arbitrario, el más profundamente racional y emocional, de la felicidad más intensiva y duradera del mayor número, se debe aceptar -claro que con especial cuidado- como el fundamento hipotético "copernicano" del juicio ético.

Que la moral del amo, de crueldad brutal contra las masas a quienes está dirigida no puede contribuir al aumento de la felicidad, es un hecho que no requiere de prueba alguna. Sin embargo, la psicología moderna y la historia nos enseñan claramente que hasta la clase dominante o la clase de los señores, con la opresión que han sembrado y la explotación de masas humanas, han cosechado más miseria que felicidad. Las alegrias auténticas, posibles así, se podrían conseguir de otro modo, al menos iguales, y sobre una base más estable. De todas maneras la agresión desconsiderada debe despertar contra-agresiones entre los pueblos, y entre las razas y las clases de los mismos pueblos; habrá también contramovimientos que sólo aumenten la destrucción originaria y sin sentido, por el mero gusto de destruir, hasta que conduzcan a un equilibrio nuevo y mejor de los intereses de los partidos.

El deseo de crueldad significa, ante todo, para el atacante, poca garantía 
de felicidad, sus placeres se vuelven superficiales, aumenta su sed de sangre "enemiga" y ese deseo sigue aumentando a medida que pasa el tiempo. La liberación de este deprimente afán de poder desconsiderado es posible únicamente por medio de la curación de este instinto patológico y por el retorno a los sentimientos normales hacia los demás hombres.

Por el contrario, en cuanto la moral del señor, en el sentido de Zarathustra, va contra el ablandamiento y la falta de realismo de una moral del amor ciego, débil y sin condiciones, es superior por la creación de condiciones auténticas de felicidad, a las esperanzas utópicas en un reino del amor sin fuerza ni poder donde todo se perdona. Solamente así, en la medida en que los resultados emocionales de nuestras acciones nos sirven como criterios morales últimos, se puede crear un terreno neutral en el que es posible comprender y juzgar sin prejuicios, contradicciones irreconciliables como las que hay entre la moral del señor y la moral del rebaño.

Con lo anterior quedan superados, desde luego, para la valoración ética, los antiguos y usuales llamados a los criterios elementales y sencillos. Ya no puede concederse que hasta en las cuestiones morales más difíciles el más ingenuo, "el entendimiento humano común" más simple, pueda tener sin más en las manos un juicio bien fundado. Ya no es factible aceptar que el corazón humano lleve marcadas con letras de fuego las leyes morales, tan fuertemente, que ninguno pueda ignorar sus admoniciones. Es cierto que desde tiempos inmemoriales existe la creencia de que en la moral no hace falta, en lo más mínimo, la "inteligencia de los inteligentes", de que la supera el simple instinto del hombre común; pero claro está que dicha antigua creencia tiene sus raices no tanto en la fe en el "espíritu infantil" del hombre común, sino más bien en el miedo, fácil de comprender, a la complicada relativización de las leyes morales. Pero esa confianza en un código moral, simple, elemental, fácilmente comprensible y de validez absoluta, no es más que la ilusión de una seguridad falaz que, en tiempos de grandes crisis, es quizá más peligrosa aún que confesar francamente las dificultades implicadas en las decisiones morales de importancia fundamental que tienen que ir más allá de las conductas habituales ordenadas moralmente. No sólo filosófica sino también políticamente me parece indispensable conceder mejor que no basta con pedir simples intenciones fundamentales, válidas absolutamente, sino que solamente por medio de una comprehensión real y del aprecio de los efectos emocionales de las conductas humanas, sólo de este modo puede uno llegar a captar las soluciones profundamente morales en los conflictos humanos más decisivos. De la misma manera que en la física su camino nos lleva a un análisis cada vez más sutil de las sensaciones ${ }^{11}$ y no a conceptos fundamentales a priori, vacios de todo contenido de percepción sensible, así

11 Ver Ernst Mach, Die Analyse der Empfindungen und das Verhältnis des Physischen zum Psychischen, 19oo. 
también en la ética hay que seguir el camino que en lugar de llevarnos a unos principios de la intención ya firmemente establecidos, nos lleve al análisis penetrante de los sentimientos, de los "resultados" de las acciones humanas.

4. Fundamentación teórica de la ética y moral metafísica, poética y religiosa

$¿ Q u i e r e$ decir lo anterior que hay que negar en la ética las grandes y antiguas especulaciones metafísicas, religiosas y poéticas sobre el sentido de la existencia y el valor de nuestra vida, que hay que sonreírse de ellas como de fantasías sin crítica alguna? ¿Hay que reemplazarlas por una árida "aritmética moral", por un cálculo racional estéril acerca de las cantidades, intensidades, duración, posibilidades e imposibilidades, seguridades e inseguridades, lejanía o proximidad, fertilidad o esterilidad, pureza o impureza, de nuestros sentimientos de placer y dolor? Este cálculo apenas sería factible como computación exacta y tampoco es necesario en todos los casos, ya que con tales cálculos quedaría ahogada la posibilidad de toda empresa ética. Nada está más lejos de las consideraciones que vamos a esbozar que todo ello.

Las especulaciones éticas y metafísicas de las grandes religiones mundiales, representan un enorme tesoro de interpretación y comprehensión de la vida humana y sólo el deseo trivial de aclarar todo puede desecharlas como anticuadas. Es cierto que un pensador tan agudo como Ludwig Wittgenstein declaró hace poco: "de lo que no se puede hablar más vale callar". ${ }^{12}$ Lo que parece una frase muy plausible y plena de valor científico para la crítica de toda meditación "a-científica", me parece en verdad una de las más vanidosas y limitadas declaraciones de la historia de la filosofía. Sin tomar en cuenta lo "indecible" que los grandes intérpretes de las acciones y sentimientos humanos supieron expresar en imágenes y parábolas, toda ética y, en general, toda filosofía se ve reducida a un triste y pobre "amor a la sabiduría".

Hasta en las más estrechas y arriesgadas visiones intuitivas de los grandes fundadores de religiones, de los metafísicos y los poetas, encontramos obviamente mayor y más auténtica comprehensión de los valores vitales que en las correctas trivialidades de los moralistas temerosos y limitados. En una sola parábola del Sohar en la canción de Buda, "La hija del platero" 13 (con su rebelión desesperada contra el placer ordinario y su glorificación del placer más alto del ascetismo); en un verso de Hölderlin puede encontrarse más sabiduría ética que en muchos volúmenes de sistemas morales de tipo convencional.

Sin embargo, a pesar de la enorme riqueza de indicaciones éticas vitales,

12 Ludwig Wittgenstein, Tractatus Logico-Philosophicus, London, 1922, pág. 188.

13 Ver de Karl Eugen Neummans, Ubertragungen der Reden Gotamo Buddhos, 1924, S. 81 ff. Subha, Des Goldschmieds Tochter. 
del mundo de los grandes poemas, de los grandes mitos, de las grandes religiones, las interpretaciones éticas se cruzan y entrelazan y a menudo se enfrentan real o aparentemente como opuestas e inconciliables. La gran plenitud de comprehensión de la vida que se encuentra en el arte, en la mística y en la especulación filosófica de todos los tiempos, resulta objetivamente inutilizable sin la aplicación del criterio, del examen imparcial del juicio moral. Careciendo del fundamento de una teoría crítica del conocimiento en la ética, todo, hasta los monumentos más sublimes de la interpretación de la existencia humana, estarían construidos sobre arena.

El apelar a las más altas intenciones, a una voluntad pura formal, al fiel cumplimiento del deber, a los principios rigurosamente establecidos de la justicia, a una serie de valores absolutamente válidos como la santidad, el amor, el valor y el honor, todo esto es seguramente aún, hablar en metáforas poéticas con sentido multivoco. El pensador ético, que por principio sólo quiere basarse sobre tales conceptos "poéticos" fundamentales, sobre un "ordre du coeur" fijo y listo, operará, por decirlo así, sólo con símbolos, con signos abreviados de magnitudes desconocidas, con cifras que requieren aún mayor determinación, pero que de ninguna manera pueden transmitir el sentido preciso del mensaje, sin el uso de la clave adecuada como pudiera parecerlo a una mirada rápida y superficial.

Las catástrofes mundiales a las que puede conducir el recurso, carente de juicio, a los grandes mitos, a las intenciones sublimes y heroicas, ha sido mostrado con no menor crueldad en nuestro propio siglo que en las horripilantes matanzas de los tiempos bárbaros del pasado. La significación de los mitos moralmente profundos, las palabras simbólicamente poéticas como amor, honor, y sentimiento del deber, para la formación concreta de nuestra vida ética, debe traducirse primero al lenguaje del placer y el dolor, antes de adquirir una significación objetiva para el juicio ético imparcial. Sólo por medio de un análisis de la felicidad y del sufrimiento, o sea de las consecuencias de las conductas dictadas por aquellas intenciones, puede prepararse el terreno para una valoración sin prejuicios de estos supuestos valoresesencias e intenciones morales en sí.

No cabe duda de que esa comprehensión y apreciación del placer y del dolor, que el aclarar los resultados pasados y futuros de la conducta humana con todas sus complejidades emocionales, requiere una capacidad de juzgar mucho mayor que el basarse simplemente sobre unas pocas intenciones y leyes fundamentales o incluso sobre un gran número de valores absolutamente válidos. Los pocos grandes campeones del hedonismo ético han sido malinterpretados sobre todo en la medida en que se creyó que con la proclamación del placer como criterio de valor, se había acabado ya el trabajo del hedonista consecuente, mientras que en verdad esa proclamación no representaba sino el comienzo. 
Aquí se trata de aprender, è un ámbito más amplio que las experiencias de felicidad y dolor que la historia nos muestra, de los más sutiles y corrientes sufrimientos y alegrías de que nos cuentan los poetas y los conocedores de la naturaleza humana de todos los pueblos. Al juez de las grandes decisiones morales no puede serle extraño ningún rasgo o inclinación de los sentimientos humanos; tienen que poder presentársele, al menos, en la "proyección sentimental". Una lucidez mental absoluta e imparcial tiene que ir unida a una comprehensión intuitiva y a una amplitud emocional de visión. Cuando se trata de esclarecer la oscuridad espantosa que amenazaba a menudo con ocultar el valor natural de la existencia y del actuar humanos, hasta a los más grandes profetas morales como Cristo o el autor del Libro de Job, no es bastante entonces ninguna de las fuerzas fundamentales del espíritu humano - ni el entendimiento ni la intuición- - sin unirse a todas las demás, a fin de dar lo máximo de sus posibilidades para alcanzar esa meta.

La averiguación de lo que signifique la felicidad más intensa y duradera o el sufrimiento más largo y pesado, en general y en casos particulares, no es un esfuerzo superficial de unos pensadores, ciegos buscadores de placer, llamados hedonistas. Esta averiguación es el problema más sagrado, más importante del espiritu humano inquisitivo. Para la interpretación del fenómeno originario del placer y el dolor deben coincidir en último término toda ética y buena parte de la filosofia de la religión, tanto más cuanto que la situación del problema permaneció bastante oculta a pesar de todos los discursos sobre la significación vital de la condenación plena de dolor y la luminosa bienaventuranza.

Durante demasiado tiempo se ha intentado despreciar, como vulgares, a las fuerzas más elementales que se mueven en la vida moral y construir sistemas éticos sobre ideas abstractas como el derecho natural universal, los valores ideales, un imperativo categórico absolutamente válido en sí, libres de "elementos vitales tan subjetivos", tan "triviales" como la alegría y el dolor. Durante siglos se buscó una interpretación universalmente convincente de los fenómenos naturales basada en parecidos conceptos puros abstractos, como la "sustancia", idea pura de la cosa, "el ser de los entes" o la "mónada", hasta que la moderna ciencia natural y el pensamiento crítico en la filosofía trajeron la autorresignación que permitió dar un papel importante a las percepciones sensibles en la verificación de las leyes de la naturaleza. Exactamente lo mismo habria que iniciar hoy en dia frente a la grave crisis de los fundamentos de la ética contemporánea. ${ }^{14} \mathrm{El}$ viejo temor de que la vuelta a las "sensaciones subjetivas inestables" podría poner en peligro la validez objetiva de las leyes científicas y éticas, no sólo es infundado sino que

14 He aspirado a una teoría semejante del sentido de la vida, en mi tomo sobre Jeremy Bentham and the Ethics of Today, 584 páginas, Princeton University Press, 1952, y en una obra sistemática más importante casi terminada. 
representa una amenaza para la ética de nuestra generación. La cimentación última del juicio ético en las vivencias más simples y originarias del hombre no significa, en modo alguno, un empobrecimiento de su vida espiritual, al contrario, sólo esto puede abrir el camino para un campo mucho más rico de investigación ética más auténtica que la realizada hasta ahora.

David BaumgardT

(trad. de Ricardo Guerra) 